\title{
Endosülfan ve Metabolitlerinin Su Örneklerinde Vorteks Destekli Sıvı-Sıvı Mikro Ekstraksiyon ve Yüksek Performanslı Sıvı Kromatografi Kullanılarak Analizi
}

\author{
Mehmet TÜRKYILMAZ ${ }^{1 *}$, Sezen KÜÇÜKÇONGAR ${ }^{1}$ \\ ${ }^{1}$ Konya Technical University, Department of Environmental Engineering, Konya, Turkey
} (ORCID: 0000-0001-5484-571X) (ORCID: 0000-0001-6444-4397)

\begin{abstract}
$\ddot{O} z$
Endosülfan doğal yollarla bozunmaya karşı mukavemetinin yüksek oluşu, canlılarda biyobirikim özelliği ve çevresel taşınımı nedeniyle, yasal kullanımlarının durdurulması sonrasında bile çevresel numunelerde tayin edilebilmektedir. Bununla birlikte endosülfan daha yüksek toksisiteye sahip ana metabolitlerine parçalanabilmektedir. Bu durum çevre ve halk sağlığ 1 açısından risk oluşturabilmektedir. Bu nedenle endosülfan kaynaklarının ve giderim yöntemlerinin belirlenmesinde endosülfan ve metabolitlerinin birlikte analiz edilmesi önemlidir. Bu çalışmada endosülfan ve metabolitlerinin birlikte analizlerinin yapılmasında vorteks destekli sıvısıvı mikroekstraksiyon (VALLME) ve sıvı kromatografi analizi yöntemi uygulanarak geri kazanım çalışmalarının optimizasyonu yapılmıştır. Endosülfan izomerlerinin ve metabolitlerinin ayrılması ve saptanması için GL science C18 reversed phase kolon ve UV/VIS/PDA ikili absorbans detektörü içeren Shimatzu Prominence-i 2030- 3d sıv1 kromatograf cihazı kullanılmıştır. $1 \mathrm{~mL} / \mathrm{dk}$ akış hızında asetonitril:su karışımı (70:30, v:v) mobil faz olarak kullanılmıştır. Endosülfan lakton, endosülfan sülfat, endosülfan eter, $\beta$-endosülfan ve $\alpha$-endosülfan, sırasıyla 214 nm'de kolonda tutulma sürelerine göre belirlenmiştir. Yüksek Performanslı Sıvı Kromatografi (HPLC) analizinden sonra en iyi kromatogram n-hekzan solventi ile elde edilmiş; bu nedenle bu solvent için en yüksek geri kazanım değerlerinin elde edilmesinde numune hacminin, solvent hacminin ve ekstraksiyon süresinin etkileri deneysel olarak araştırılmış ve değişkenler için optimal koşullar sırasıyla $10 \mathrm{~mL}, 200 \mu \mathrm{L}$ ve 3 dakika olarak elde edilmiştir. Optimum koşullar altında, endosülfan lakton, endosülfan sülfat, endosülfan eter, $\beta$-endosülfan ve $\alpha$-endosülfan için geri kazanım oranları sırasıyla \%115.31, \%91.1, \%96.79, \%103.06 ve \%99.06 olarak belirlenmiştir. Bu çalışmada elde edilen sonuçların diğer kalıcı kirleticilerin ve metabolitlerinin de eş zamanlı tayini ve çevresel matrislerde izlenmesi konusundaki çalışmalara katkı sağlayacağı düşünülmektedir.
\end{abstract}

Anahtar kelimeler: Endosülfan, metabolit, Vorteks ekstraksiyonu, Sıv1 kromatografisi.

\section{Analysis of Endosulfan and its Metabolites in Water Samples Using Vortex Assisted Liquid-Liquid Micro Extraction and High Performance Liquid Chromatography}

\begin{abstract}
Endosulfan can be detected in environmental samples even after their legal use is stopped, due to their high resistance to natural degradation, bioaccumulation and environmental transport. However, endosulfan can be broken down into major metabolites with higher toxicity. This may pose a risk to the environment and public health. Therefore, it is important to analyze endosulfan and its metabolites together in determining endosulfan sources and removal methods. In this study, method optimization experiments were performed in the analysis of endosulfan and its metabolites together by vortex assisted liquid-liquid microextraction (VALLME) and liquid chromatography analysis method. Shimadzu liquid chromatograph device equipped with GL science C18 reversed phase column and UV/VIS/PDA dual absorbance detector was used for separation and detection of endosulfan isomers and metabolites. Acetonitrile:water mixture $(70: 30, \mathrm{v}: \mathrm{v})$ at a flow rate of $1 \mathrm{~mL} / \mathrm{min}$ was used as the mobile
\end{abstract}

*Sorumlu yazar: mturkyilmaz@ktun.edu.tr

Geliş Tarihi: 29.06.2021, Kabul Tarihi: 18.10.2021 
phase. Endosulfan lactone, endosulfan sulfate, endosulfan ether, $\beta$ - endosulfan and $\alpha$ - endosulfan were determined according to retention times in the column at $214 \mathrm{~nm}$, respectively. After HPLC (High Performance Liquid Choromatography) analysis, the best chromatogram was obtained with n-hexane solvent; therefore, the effects of sample volume, solvent volume and extraction time in obtaining the highest recovery values for this solvent were experimentally investigated and optimal conditions for variables were obtained as $10 \mathrm{~mL}, 200 \mu \mathrm{L}$ and $3 \mathrm{~min}$, respectively. Under optimum conditions, recovery rates for endosulfan lactone, endosulfan sulfate, endosulfan ether, $\beta$ - endosulfan and $\alpha$ - endosulfan were $115.31 \%, 91.1 \%, 96.79 \%, 103.06 \%$ and $99.06 \%$, respectively. It is thought that the results obtained in this study will contribute to on the simultaneous determination and monitoring studies in environmental matrices of other persistent pollutants and their metabolites.

Keywords: Endosulfan, Metabolite, Vortex extraction, Liquid chromatography.

\section{Giriş}

Endosülfan çay, kahve, pamuk, meyve, sebze, pirinç ve tahıl dâhil olmak üzere bitkilerdeki çok çeşitli böcekler ve akarlar için uygulanan siklodien alt grubuna ait klorlu hidrokarbon insektisit ve akarisittir [1]. Endosülfanın kimyasal adı 6,7,8,9,10,10-hekzakloro-1,5,5a,6,9,9a-hekzahidro-6, 9-metano-2,4,3benzo (e) dioksitiepin 3-oksit, kimyasal formülü ise $\mathrm{C}_{9} \mathrm{H}_{6} \mathrm{Cl}_{6} \mathrm{O}_{3} \mathrm{~S}^{\prime}$ dir. Tiyonilklorürün tiyodan ile reaksiyona girmesiyle oluşur. Teknik endosülfan, $\alpha$ ve $\beta$ olarak adlandırılan 70: 30 stereoizomer karışımıdır [2].

Endosülfanın hidroliz, fotoliz, oksidasyon ve biyodegradasyon yollarıyla doğal bozunması endosülfan sülfat, endosülfan lakton, endosülfan eter, endosülfan alkol ve endosülfan diol metabolitlerinin oluşumuna yol açar. Endosülfanın bilinen tüm doğal bozuma ürünleri, endosülfanın orijinal klorlu halka yapısını korur ve toksik ve potansiyel kanserojendir. Çalışmada kullanılan izomer ve metabolitlerinin açık formülü Şekil 1'de verilmiştir. Tescil edildiği 1954 yılından 2000 yılına kadar tarında kümülatif kullanımının 308.000 ton olduğu belirtilmektedir [3]. Bu pestisitin küresel tüketimi 1980'lerin başında yaklaşık 9000 ton/yıl iken, 1990'larda 12800 tona yükseldiği ve küresel ölçekte yasaklandığ 2010 yılına kadar ise dünya çapında endosülfan üretiminin 18000-20000 ton/y1l aralığında olduğu tahmin edilmektedir [4]. Ekosistemdeki yaygın kullanımı, kalıcılığı, biyolojik birikimi, uzun menzilli taşınımı, endokrin sistemini bozması ve (Memeliler de dahil olmak üzere bir dizi organizmaya karşı potansiyel toksisiteleri nedeniyle) toksisitesi göz önünde bulundurularak endosülfan, Stockholm Sözleşmesi kalıcı organik kirleticiler (KOK) listesinin Ek A'sına 2011 yılında eklendi [5] , üretimi ve kullanımı 2012 ortasından beri dünya çapında yasaklanmıştır [6].

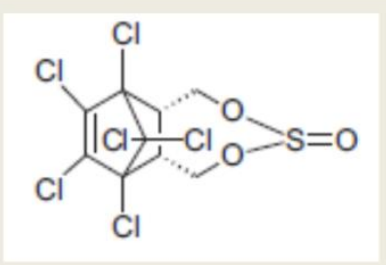

$\alpha$ endosülfan

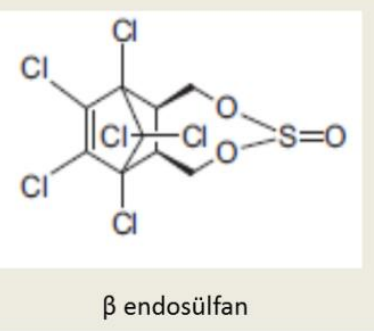

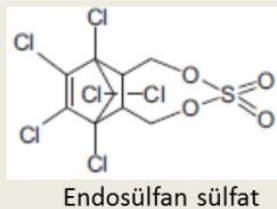
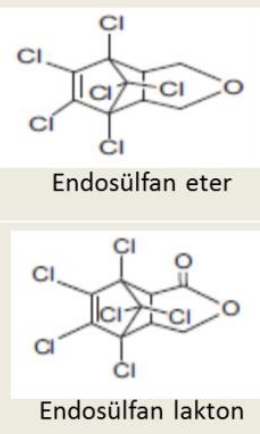

Şekil 1. Endosülfan izomer ve ana metabolitlerinin kimyasal yapısı [7].

Çevresel ortamlarda endosülfan tayininde farklı analitik teknikler kullanılmıştır. Bunlar, yüksek performanslı sivı kromatografisi (HPLC), gaz kromatografisi (GC), gaz kromatografisi-kütle spektrometrisi (GC-MS) ve kolorimetrik yöntemlere dayanmaktadır. Bununla birlikte, HPLC ve GC yöntemi, kolorimetrik yöntemlerin aksine, endosülfan miktarının belirlenmesi için nispeten daha uygun 
kabul edilir. Cihazda analizden önce, numunede ekstraksiyon, ön konsantrasyon işlemi uygulanması ve ardından endosülfanın kantitatif tayininin yapılması gerekmektedir.

HPLC analizinde, hedef bileşiklerin karışımına sahip ekstrakte edilmiş numune, hareketli sıvı faz kullanılarak 400 atm'ye kadar yüksek basınç altında, genellikle bir kolon içinde sabit bir katı fazdan geçmesine izin verilerek bileşenlere ayrılır. Numunenin bileşenleri, çeşitli kimyasal veya fiziksel etkileşimler nedeniyle kolon paketiyle ayrılır ve ayrılan bileşenler daha sonra kolonun çıkışında harici bir detektör tarafindan tespit edilir. Analiz için ortak mobil faz, metanol veya asetonitril ve sudan oluşan bir karışımdır.

Çevresel matrislerden pestisitlerin en yaygın ekstraksiyon yöntemleri arasında sıv1-sıv1 ekstraksiyonu (LLE) ve katı faz ekstraksiyonu (SPE) bulunur. Bununla birlikte, bu geleneksel ön muamele yöntemleri büyük miktarlarda numune ve/veya organik çözücülere ihtiyaç duyar, zaman alıcı, pahalıdır ve kullanılan malzemeler tekrar kullanılamaz [8]. Son yıllarda, numune ön işleme tekniklerinde, hem malzeme hem de personel maliyetlerini düşürmek için esas olarak minyatürleştirme, basitleştirme ve otomasyona odaklanılmışıır [9]. Bu eğilim, sıvı faz mikro ekstraksiyon (LPME), tek damla mikroekstraksiyon (SDME), hollow fiber siv1 faz mikroekstraksiyonu (HF-LPME), dispersive sıv1-sıv1 mikroekstraksiyonu (DLLME) ve katılaşmış yüzen organik damla mikroekstraksiyonu (SFODME) gibi birçok mikroekstraksiyon tekniğinin geliştirilmesiyle sonuçlanmıştır. Bu teknikler operasyonun basitliği, nispeten düşük enstrümantasyon maliyetleri, çok yönlülük, kromatografik sistemlere kolay bağlantı ve kısa ekstraksiyon süresi dahil birçok olumlu özelliğe sahiptir [10].

Yiantzi ve ark. [11] ekstraksiyon çözücüsünün dispersiyonunun vorteks karıştırmayla güçlendirildiği vorteks destekli sıvı-sıvı mikro-ekstraksiyon tekniği geliştirilmiştir. Yöntem, mikrolitre düzeyindeki özütleme çözücüsünü sulu numuneye dağıtmak için düşük maliyetli ve etkili bir yöntem olarak vorteks çalkalamayı kullanmaktadır. İnce damlacıkların üretilmesi, kütle transferi için mevcut olan arayüzey alanını büyük ölçüde artırmakta, difüzyon mesafesini düşürmekte ve ekstraksiyon oranlarını geliştirmektedir, böylece analitler birkaç dakika içinde ayırma dengesine ulaşabilmektedir. Ekstraksiyonun ardından, iki sıvı faz santrifüjleme ile ayrılmakta ve alıcı faz geri kazanılarak analiz için kullanılmaktadır.

Herhangi bir kirleticinin üretimine ve kullanımına yasal bir sınırlandırma getirilmesi halinde, mevcut stoklar tüketilinceye kadar yasal olmayan kullanımlarının takip edilmesi oldukça zordur. $\mathrm{Bu}$ nedenle endosülfanın en son yasaklanan kimyasal maddelerden biri olması nedeniyle, çevresel ortamlarda mevcudiyetinin yüksek olabileceği tahmin edilmektedir. Özellikle kalıcı organik madde sınıfinda olması sebebiyle bu kirletici maalesef daha uzun y1llar bir kirletici olarak gündemimizde olması gereken, takibi ve gideriminin incelenmesi gerekli olan bir pestisit olacaktır. Çevresel matrislerdeki pestisit kalıntılarının belirlenmesi, öncelikle bunların ekstraksiyonuna ve zenginleştirilmesine bağlıdır. Bununla birlikte, geleneksel ön muamele yöntemleri büyük miktarlarda numune ve/veya organik çözücülere ihtiyaç duyar, zaman alıcı, pahalıdır ve kullanılan malzemeler tekrar kullanılamaz. Bu zorlukların üstesinden gelmek için kalıcı organik kirleticilerin basit, hızlı, düşük solvent tüketimini ve düşük atık üretimini içeren, yüksek zenginleştirme faktörlerine ulaşıldığ 1 çevre dostu veya yeşil analitik kimya prosedürlerinin kalıcı organik kirleticilere uygulanması planlanmıştır. $\mathrm{Bu}$ amaçla, çalışmada, organoklorlu pestisit grubundan $\alpha$-endosülfan, $\beta$-endosülfan, endosülfan sülfat, endosülfan lakton ve endosülfan eterin eş zamanlı olarak sentetik sulu numunelerden ön konsantrasyonu için bir VALLME numune hazırlama yönteminin optimizasyonu gerçekleştirilmiştir. Ekstraksiyon solventinin tipi ve hacmi, numune hacmi ve ekstraksiyon süresinin optimizasyonu yapılmıştır. Optimize edilen yöntem ile organoklorlu pestisit grubundaki diğer kalıcı kirleticilerin ve metabolitlerinin de eş zamanlı ekstraksiyonun etkili bir şekilde yapılmasına 1şık tutacağı düşünülmektedir.

\section{Materyal ve Metot}

\subsection{Kullanılan Kimyasallar}

Endosülfan izomerleri ve metabolitlerinin standart ve stok çözeltilerinin hazırlanması için kromatografik saflıkta $\alpha+\beta$-endosülfan (\%99.5), $\alpha$-endosülfan (\%99.5), $\quad \beta$-endosülfan (\%99.3), endosülfan sülfat (\%98.0), endosülfan lakton (\%99.0) ve endosülfan eter (\%99.0) Sigma Aldrich, çözücü olarak kullanılan aseton ise Merck KGaA firmasından temin edilmiştir. Endosülfan izomerleri ve metabolitlerinin ekstraksiyonunda kullanılmak üzere yüksek saflıkta solventler; diklorometan $\left(\mathrm{CH}_{2} \mathrm{Cl}_{2}\right)$, dietileter $\left(\mathrm{C}_{2} \mathrm{H}_{5}\right)_{2} \mathrm{O}$, etilasetat $\left(\mathrm{C}_{4} \mathrm{H}_{8} \mathrm{O}_{2}\right)$, trikloretilen $\left(\mathrm{C}_{2} \mathrm{HCl}_{3}\right)$, tetrakloretilen $\left(\mathrm{C}_{2} \mathrm{Cl}_{4}\right)$, 1,2- 
diklorobenzen (1,2-( $\left.(\mathrm{Cl})_{2}\left(\mathrm{C}_{6} \mathrm{H}_{4}\right)\right)$ Tekkim; siklohekzan $\left(\mathrm{C}_{6} \mathrm{H}_{12}\right)$, toluen $\left(\mathrm{C}_{7} \mathrm{H}_{8}\right)$ Carlo Erba; n-hekzan $\left(\mathrm{C}_{6} \mathrm{H}_{14}\right)$, Merck $\mathrm{KGaA}$ ve kloroform $\left(\mathrm{CHCl}_{3}\right)$ Akkimya firmlarından temin edilmiştir.

\subsection{HPLC Enstrümantasyon ve Kromatografik Koşullar}

Endosülfan izomerlerinin ve metabolitlerinin tayini $44 \mathrm{MPa}$ basınç ve $10 \mathrm{~mL} / \mathrm{dk}$ akış kapasitesine sahip ikili HPLC pompalarından oluşan, inceltilmiş bir akış hücresi ile 190 ila $700 \mathrm{~nm}$ arasında çalışan ve bir GL Science C18 (250 mm x $3.1 \mathrm{~mm}$ i.d.) reversed phase kolon üzerinde ayrılan iki kanallı bir UV/VIS/PDA ikili absorbans dedektörü kullanılarak Shimadzu Prominence-i 2030- 3d sıv1 kromatografi sistemi ile gerçekleştirilmiştir. Kolon sicaklığı ortam sicaklığında kullanılmış ve enjeksiyon otomatik numune örnekleyicisi ile gerçekleştirilmiştir. Mobil faz, $1 \mathrm{~mL} / \mathrm{dk}$ akış hızında, hacimce 70:30 olarak ayarlanmış asetonitril:su karışımından oluşturulmuştur. Enjeksiyon hacmi $20 \mu \mathrm{L}$ olarak belirlenmiş ve endosülfan ve metabolitleri 214 nm'de tespit edilmiştir.

\subsection{Standart Çözeltilerin Hazırlanması}

$\alpha$-endosülfan, $\beta$-endosülfan, endosülfan sülfat, endosülfan lakton ve endosülfan eter kimyasallarının 200 $\mathrm{mg} / \mathrm{L}$ konsantrasyonunda stok çözeltileri aseton içinde ayrı ayrı çözülerek hazırlanmıştır. İlk olarak izomer ve metabolitleri cihaza tanıtmak ve kolonda tutulma sürelerini tespit etmek üzere $200 \mathrm{mg} / \mathrm{L}$ konsantrasyonda, standartlar yukarıda belirtilen HPLC şartlarında cihaza enjekte edilmiştir. Kalibrasyon grafiğinin oluşturulması için ise stok çözeltilerden istenilen farklı konsantrasyonlarda $(10,20,50,100$ ve $150 \mathrm{mg} / \mathrm{L}$ ) aseton ile seyreltmeler yapılmış, sonrasında cihaza enjekte edilerek konsantrasyona karşılık elde edilen pik alanları grafiğe işlenerek kalibrasyon denklemleri oluşturulmuştur.

\subsection{Endosülfan ve Metabolitlerinin Sentetik Su Numunelerinden Ekstraksiyonu}

Endosülfan izomer ve metabolitlerinin su ortamındaki analizlerinin yapılmasında VALLME yöntemi [11] uygulanmış ve yöntemde optimum şartların belirlenmesi için deneysel çalışmalar iki aşamada gerçekleştirilmiştir. Ekstraksiyon çalışmalarının ilk aşaması olarak, en uygun solvent türü belirlenmiştir. Solvent türünü belirleyebilmek için, diğer değişken parametreler/kontrol edilebilen faktörler sabit değerlerde tutulmuştur. Deneysel çalışmalarda diklorometan, dietileter, etilasetat, trikloretilen, tetrakloretilen, siklohekzan, kloroform, toluen, 1,2-diklorobenzen ve n-hekzan solventlerinin her biri, endosülfan izomerlerini ve metabolitlerini içeren $2 \mathrm{mg} / \mathrm{L}$ konsantrasyonuna sahip stok çözeltilerden hazırlanan $10 \mathrm{~mL}$ numunelere $200 \mu \mathrm{L}$ hacminde eklenmiştir. Sonrasında $1 \mathrm{dk}$ elle çalkalama, devamında ise $1 \mathrm{dk} 3000$ rpm'de vorteks karıştırma uygulanmıştır. Faz ayrımının gerçekleşmesi için 3000 rpm'de $2 \mathrm{dk}$ süreyle numuneler santrifüjlenmiştir. Santrifüj işlemi sonucunda tek damla formunu geri kazanarak en yüksek geri kazanım verimin elde edildiği solvent ekstraksiyon solventi olarak seçilmiştir.

En uygun ekstraksiyon solventi belirlendikten sonra deneysel çalışmaların ikinci aşamasında, VALLME'de daha yüksek geri kazanım oranları elde etmek için ekstraksiyon performansını etkileyen vorteks karıştırma süresi, solvent ve numune hacmi optimize edilmiştir. Optimizasyon için minimumortalama-maksimum olacak şekilde 200,300 ve $400 \mu \mathrm{L}$ solvent hacimleri; 5, 7.5 ve $10 \mathrm{~mL}$ numune hacimleri, 1,3 ve 5 dakika vorteks karıştırma süreleri çalışılmıştır.

\section{Bulgular ve Tartışma}

\subsection{Endosülfan İzomerlerinin ve Metabolitlerinin HPLC Analizi ve Kalibrasyon Denklemlerinin Elde Edilmesi}

Birçok çevresel organik kirleticinin ayrılması ve saptanması için yüksek performanslı sıv1 kromatografisi başarıyla kullanılmıştır. Yüksek performanslı sıvı kromatografisinin GC' ye göre birçok avantajı vardır. Asidik, bazik, nötr, iyonik ve termal olarak kararsız pestisitlerin eşzamanlı analizine izin verir. Bunun yanısıra, bu teknik birçok polar pestisitin ve metabolitin belirlenmesine izin vererek ön türevlendirmeyi önler ve numune manipülasyonunu en aza indirir.

Endosülfan izomerleri ve metabolitlerine ait sıvı kromatogramlar birleştirildiğinde elde edilen elde edilen kromatogram Şekil 2'de verilmiştir. 


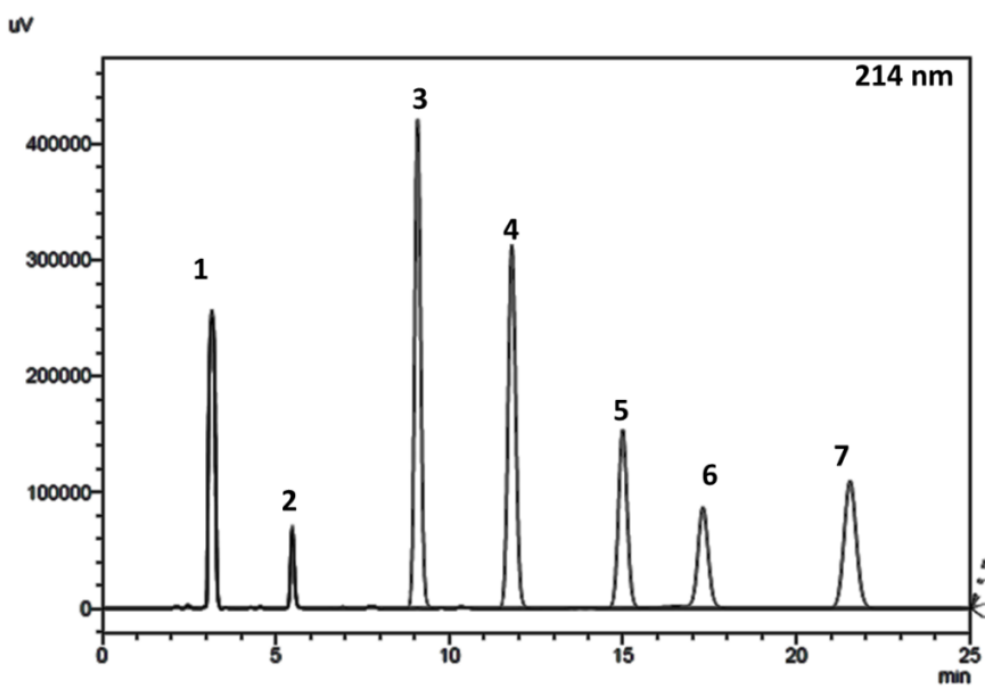

Şekil 2. Endosülfan izomerleri ve metabolitlerine ait kromatogram (1: asetonitril, 2: aseton, 3: endosülfan lakton, 4: endosülfan sülfat, 5: endosülfan eter, 6: $\beta$-endosülfan, 7: $\alpha$-endosülfan).

Kromatogramda görülen 1 nolu pik taşıyıcı faz olan asetonitril, 2 nolu pik endosülfan izomerleri ve metabolitlerine ait stok çözeltilerin hazırlanmasında kullanılan aseton ait olup alıkonma süreleri sırasıyla 3.259 ve 5.477 dakikadır. 3 nolu pik endosülfan lakton, 4 nolu pik endosülfan sülfat, 5 nolu pik endosülfan eter, 6 nolu pik $\beta$-endosülfan ve 7 nolu pik ise $\alpha$-endosülfana ait olup alıkonma süreleri, kalibrasyon denklemleri ve $\mathrm{R}^{2}$ değerleri tablo 1 'de verilmiştir.

Tablo 1. Endosülfan ve metabolitlerine ait alıkonma süreleri ve kalibrasyon verileri

\begin{tabular}{|c|c|c|c|}
\hline Analit & $\begin{array}{c}\text { Alınkonma } \\
\text { süresi }\end{array}$ & $\mathbf{R}^{\mathbf{2}}$ & Kalibrasyon denklemi \\
\hline Lakton & 9,058 & 0,9804 & $\mathrm{y}=21973 \mathrm{x}$ \\
\hline Sülfat & 11,765 & 0,9996 & $\mathrm{y}=26301 \mathrm{x}$ \\
\hline Eter & 14,948 & 0,9943 & $\mathrm{y}=15349 \mathrm{x}$ \\
\hline $\boldsymbol{\beta}$ - endosülfan & 17,249 & 0,9982 & $\mathrm{y}=8520,4 \mathrm{x}$ \\
\hline $\boldsymbol{\alpha}$ - endosülfan & 21,469 & 0,9929 & $\mathrm{y}=13069 \mathrm{x}$ \\
\hline
\end{tabular}

Tespitte doğrusallık oluşturmak için 10 ila $150 \mathrm{mg} / \mathrm{L}$ endosulfan izomer ve metabolitlerinin konsantrasyonları GL Science C18 kolonunda test edildi. Çalışılan konsantrasyon aralığında izomer ve matabolitler için iyi bir doğrusallık elde edildi.

\subsection{Endosülfan İzomerlerinin ve Metabolitlerinin Ekstraksiyonunda Geri Kazanım Çalışmalarının Sonuçları}

VALLME'de, analit ekstraksiyonu ağırlıklı olarak damla parçalanmasının ilk adımı sırasında gerçekleşir. $\mathrm{Bu}$ adım sırasında, ekstraksiyon verimliliğini optimize etmek için bir dizi deneysel parametre kontrol edilir. Bu bölümde öncelikle endosülfan izomerlerine ve metabolitlerine afinitesi en yüksek olan çözücünün tespiti yapılmıştır. Sonrasında ise ekstraksiyon yönteminin optimizasyonu için ekstraksiyon süresi, çözücü ve numune hacimleri çalışılmıştır.

En uygun ekstraksiyon çözücüsünün seçilmesi, hedef bileşiklerin seçiciliğinin daha iyi elde edilmesi için çok önemlidir. VALLME'de, suyla karışmayan birkaç organik çözücü ve iyonik sıvı, sudan daha yüksek veya daha düşük yoğunluklarda test edilmiştir [12]. Ekstraksiyon çözücüsünün sudan daha düşük bir yoğunluğa sahip olduğu durumlarda, çözücünün ikinci faz ayırma aşamasından sonra büyük bir mikro damla şeklini geri kazanma kabiliyeti dikkate alınmalıdır [11].

Ekstraksiyon işlemleri sonucunda diklorometan, 1,2 diklorobenzen, dietileter ve etilasetat çözücüleri ile yapılan deneylerde çözücü ve analitler arasındaki etkileşimi gösteren bulutsu görünüm ve santrifüj işlemi sonrası faz ayrımı gerçekleşmemiştir. Trikloretilen, tetrakloretilen, kloroform, 
siklohekzan, toluen ve n-hekzan çözücülerinde çalkalama ve vorteks süresince bulutsu oluşum gözlenmiş ve santrifüj sonrası iki sıv1 arasında faz ayrımı gerçekleşerek şeffaf bir görünüm elde edilmiştir. Siklohekzan, toluen ve n-hekzan çözücülerinde ayrım üst faz olarak elde edilirken, trikloretilen, tetrakloretilen ve kloroform çözücülerinde alt faz oluşumu gözlenmiştir. Pastör pipet kullanılarak oluşan fazlar viallere aktarılmış, HPLC cihazına enjeksiyonu gerçekleştirilmiştir. Analizler sonucunda elde edilen geri kazanım değerleri Şekil 3'de gösterilmiştir.

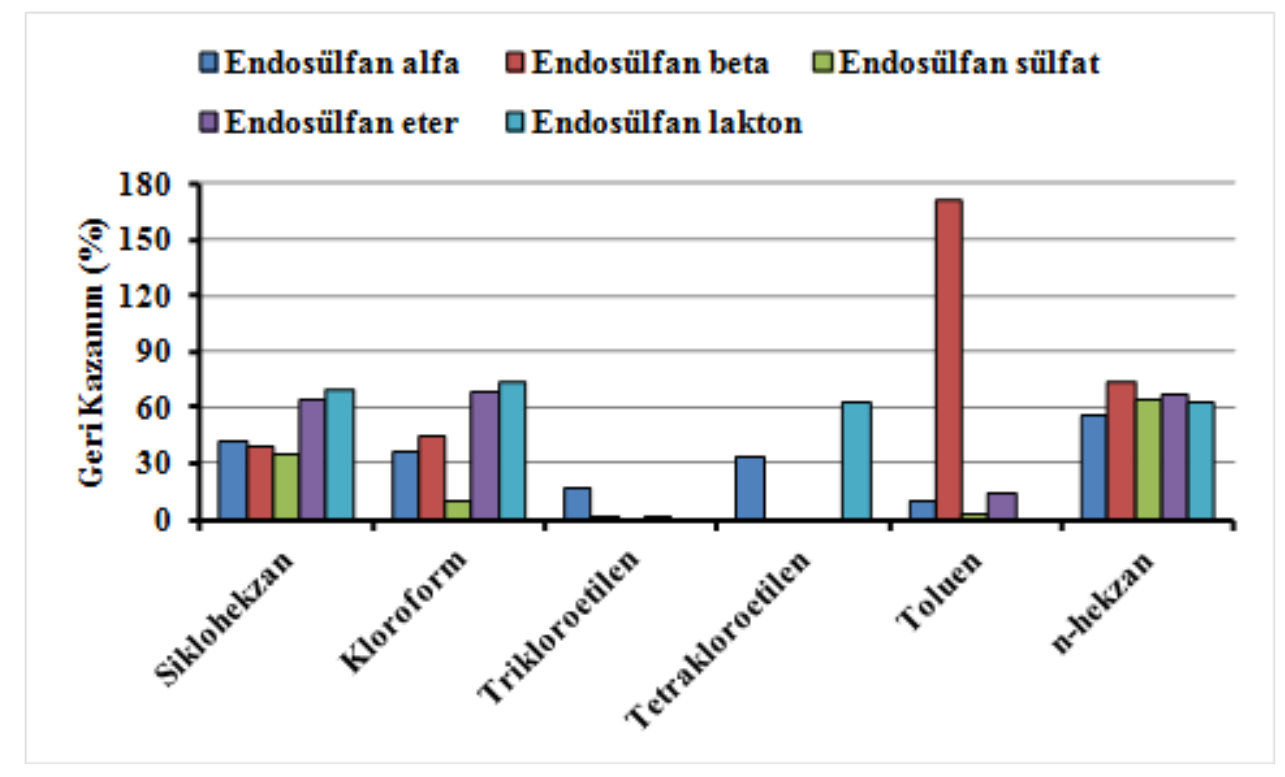

Şekil 3. Farklı çözücülerle elde edilen geri kazanım oranları $(10 \mathrm{~mL}$ numune hacmi, $200 \mu \mathrm{L}$ solvent hacmi, $1 \mathrm{dk}$ vorteks süresi).

Şekil 3'den görüleceği üzere HPLC okumaları sonrasında en iyi geri kazanım siklohekzan, kloroform ve n-hekzan çözücülerinde elde edilmiştir. Mevcut diğer çözücülerin kolonda tutulma süreleri, endosülfan izomerleri ve metabolitlerinin tutulma süreleri ile üst üste çakışarak alan ayrımlarının sağlanmasını engellemiştir (Şekil 4). Ayrıca kloroform çözücüsünde endosülfan sülfat için geri kazanım oranı çok düşük olduğundan dolayı ekstraksiyon prosesinin optimizasyon deneylerine siklohekzan ve n-hekzan çözücüleri ile devam edilmiştir. 

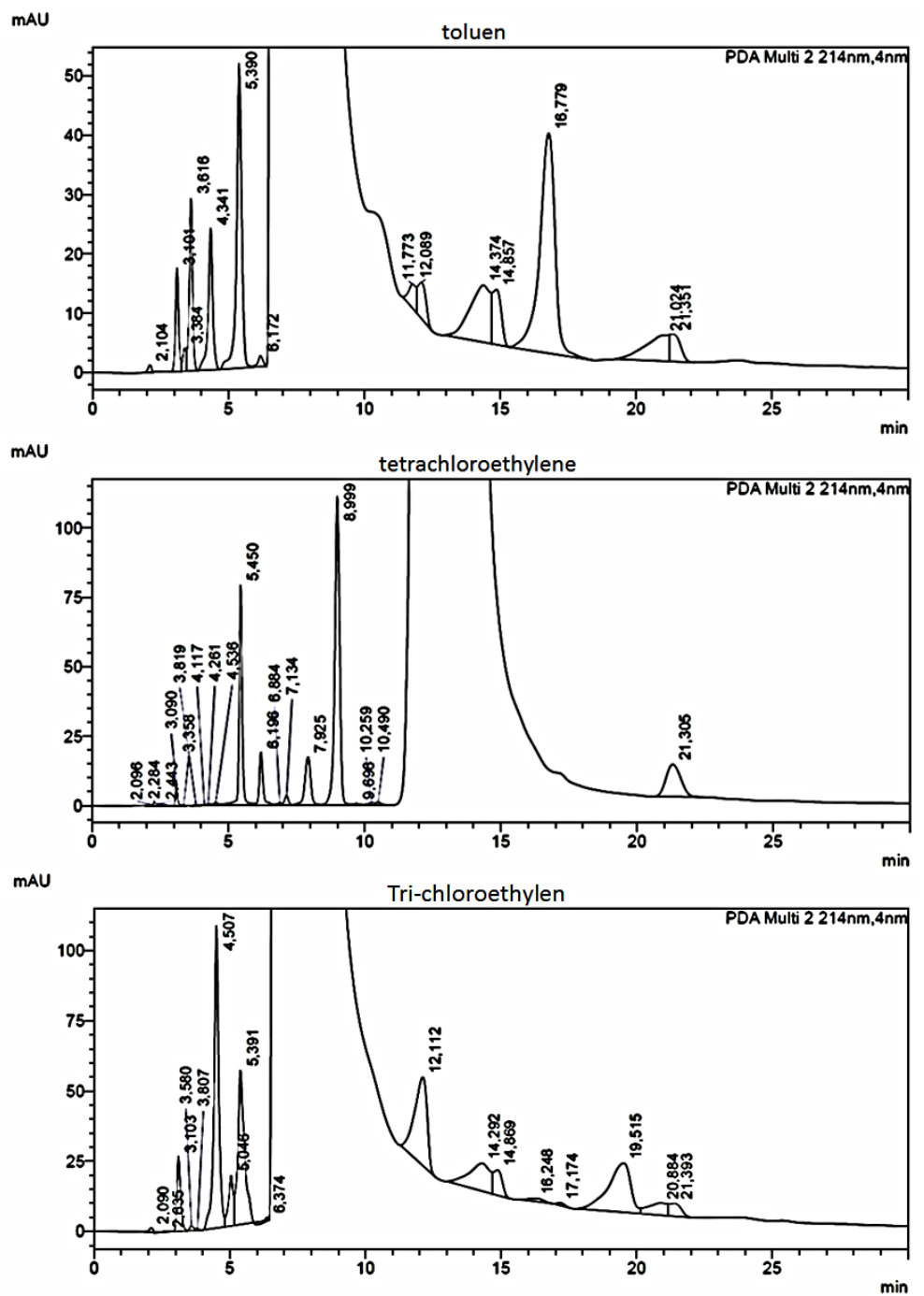

Şekil 4. Toluen, tetrakloretilen ve trikloretilen çözücüleri ile geri kazanıma ait kromatogramlar.

\section{-Çözücü hacminin geri kazanım üzerine etkisi}

Sıv1-sıvı mikroekstraksiyon işlemlerinde kullanılan ekstraksiyon çözücüsünün hacmi ekstraksiyondan sonra toplanan organik fazın hacmini, sonuçların tekrarlanabilirliğini ve ekstraksiyonun verimliliğini etkileyebileceğinden optimize edilmesi gerekir [13]. Yeterli bir çözücü, hedef analitlerin tam olarak kazanılmasını sağlar ve ideal bir iyileşme ile sonuçlanır. Ekstraksiyon çözücü hacminin artmasıyla, santrifüjlemeden sonra toplanan son çözücü hacmi artar, ancak bu analitlere karşı duyarlılıkta bir azalmaya neden olur. Hassasiyeti arttırmak için, ekstraksiyon çözücüsünün hacmini mümkün olduğunca düşük tutmak önemlidir. Bununla birlikte, çözücü hacmini istenen şekilde azaltmak her zaman mümkün değildir, çünkü kromatografik analiz için santrifüjlemeden sonra yeterli hacimde çözücünün toplanması gerekir [14]. Çözücü hacmi için optimal miktarı bulmak amacıyla, 200, 300 ve $400 \mu \mathrm{L}$ farklı solvent hacimlerini içeren deneyler, aynı ekstraksiyon koşulları altında gerçekleştirilerek elde edilen sonuçlar Şekil 5'te verilmiştir. $100 \mu \mathrm{L}$ çözücü hacmi ile gerçekleştirilen deneylerde santrifüj işleminden sonra HPLC enjeksiyonu için yeterli hacim toplanamadığından $200 \mu$ L'nin altında değerler dikkate alınmamıştır. 

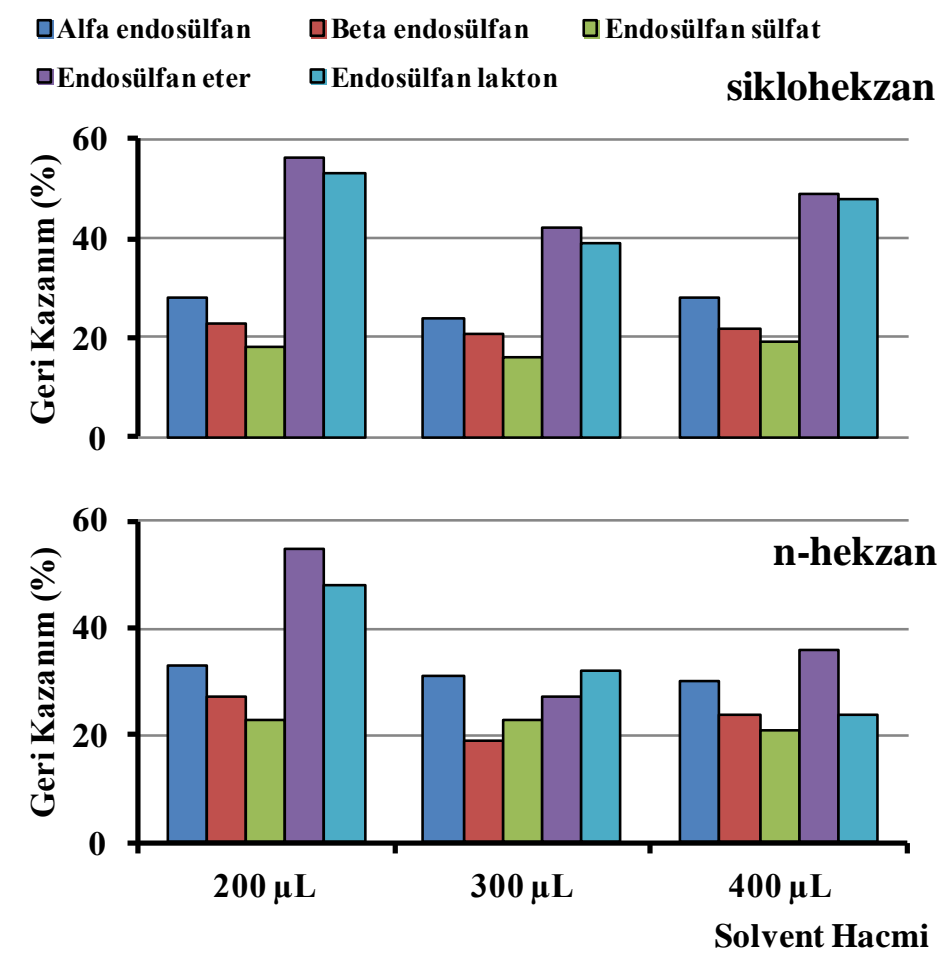

Şekil 5. n-hekzan ve siklohekzan solventleri ile yapılan geri kazanım çalışmalarına solvent hacminin etkisi (2 $\mathrm{mg} / \mathrm{L}$ endosülfan izomer ve metabolit konsantrasyonu, $5 \mathrm{~mL}$ numune hacmi, $1 \mathrm{dk}$ vorteks süresi).

Analiz sonuçları incelendiğinde çözücü miktarındaki artışın geri kazanım verimlerinde kayda değer bir yükselme sağlamadığ 1 görülebilir. Artan çözücü hacmi ile geri kazanım verimlerinde iyileşmenin gerçekleşmemesi durumu çözücü hacminin artmasıyla ekstrakte edilen analitlerin seyreltilmesi gerçeğiyle açıklanabilir [15]. Hem geri kazanım oranlarının diğerlerine nazaran yüksek olması hem de yeşil kimya prensiplerine uygun düşük miktar solvent kullanımı amacıyla $200 \mu \mathrm{L}$ optimum çözücü hacmi olarak alınmıştır. Ayrıca tüm çözücü hacimlerinde santrifüj sonrası geri kazanılan solvent hacimleri de HPLC enjeksiyonu için yeterliydi. Benzer şekilde Li ve ark. [16] gıdayla temas eden plastiklerden ftalat esterlerinin belirlenmesi için vorteks destekli sıv1-sıv1 mikroekstraksiyonu kullandıkları çalışmalarında çok az miktarda özütleyicinin, hedef analitlerin kantitatif geri kazanımı gereksinimini karşılamak ve analitik yöntemin hassasiyetini iyileştirmek için çok yararlı olan yüksek zenginleştirme oranına ulaşmak için yeterli olduğunu ifade etmiş, $80 \mu \mathrm{L}$ özütleyici hacmini optimum bulmuşlardır. Bu arada, $70 \mu \mathrm{L}$ özütleyici kullanıldığında, geri kazanılan özütleyici miktarının $50 \mu$ L'lik bir mikro şırınga kullanılarak alım için yeterli olmadığı ve bu nedenle ilgili sonuçların belirlenemediğini de belirtmişlerdir. Yiantzi ve ark. [11] yaptıkları çalışmada çözücü hacmini $50 \mu \mathrm{L}$ 'den $80 \mu \mathrm{L}$ 'ye çıkardıklarında bisfenol-A, oktilfenol ve nonilfenol geri kazanım verimi için sırasıyla \%36, 38 ve 42'lik bir azalma kaydetmişlerdir. Bunun nedenini ise çözücü fazındaki hedef analitlerin nihai konsantrasyonlarının azalmasıyla açıklamışlardır.

\section{-Numune hacminin geri kazanım üzerine etkisi}

Numune hacmi, ekstraksiyon geri kazanımını iki açıdan etkileyebilir. İlk olarak, daha yüksek bir numune hacmi daha fazla ekstraksiyon çözücüsünü çözebilir ve bu da ekstraksiyon verimliliğini doğrudan düşürebilir [17]. İkinci olarak, daha büyük bir numune hacmi daha fazla miktarda hedef analit içerir; böylece ekstraksiyonu artırır ve yöntem duyarlılığını iyileştirir [18]. Geri kazanım oranlarını artırabilmek adına numune hacmi, kullanılan ekstraksiyon kabına ve yöntemin sonuçtaki hassasiyetine bağlı olarak 5, 7.5 ve $10 \mathrm{~mL}$ alınarak ve diğer şartlar aynı kalacak şekilde siklohekzan ve n-hekzan çözücüleri için optimize edilmiştir. 

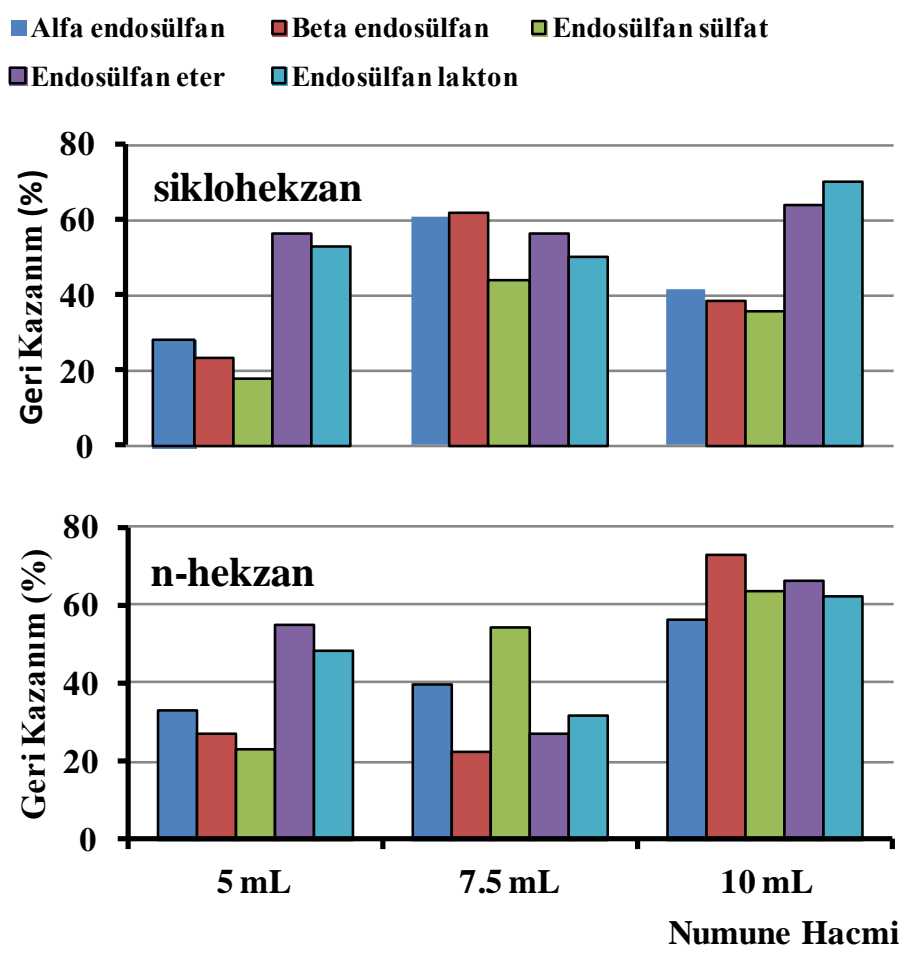

Şekil 6. n-hekzan ve siklohekzan solventleri ile yapılan geri kazanım çalışmalarına numune hacminin etkisi (2 $\mathrm{mg} / \mathrm{L}$ endosülfan izomer ve metabolit konsantrasyonu, $200 \mu \mathrm{L}$ solvent hacmi, $1 \mathrm{dk}$ vorteks süresi).

Şekil 6'da görüleceği üzere numune hacmindeki azalma ile yeterli geri kazanım oranları elde edilemediği gibi oranlarda düşüş gerçekleşmiş ve numune hacmindeki azalmanın geri kazanım oranlarını düşürdügü sonucuna ulaşılmıştır. Sonraki deneylerde kullanılmak üzere en iyi verimlerin elde edildiği $10 \mathrm{~mL}$ numune hacmi optimum değer olarak alınmıştır. Yiantzi ve ark. [11] yaptıkları çalışmada, numune hacminin $5 \mathrm{~mL}$ 'den $20 \mathrm{~mL}$ 'ye yükseltilmesi ile ekstraksiyon için mevcut olan toplam analit kütlesinin arttırıldığını, bunun da bisfenol-A, oktilfenol ve nonilfenol için analitik cihazın yanıtında net bir artışa neden olduğunu ve kaydedilen sinyallerin sırasıyla 1.5, 2.4 ve 3.4 kat daha yükseldiğini ifade etmiştir. Papadopoulou ve ark. [19] yaptıkları çalışmalarında perflorooktan sülfonat ekstraksiyonunda, $5 \mathrm{~mL}$ numune hacmi elde edilen geri kazanım verimlerine kiyasla $20 \mathrm{~mL}$ numune hacminde elde edilenleri yaklaşı 4.3 kat daha büyük tespit ederek optimum numune hacmini $20 \mathrm{~mL}$ olarak almışlardır.

\section{-Vorteks süresinin geri kazanım üzerine etkisi}

Sıv1-sıv1 ekstraksiyon metodolojisinde, hedef analitin sulu fazdan ekstraksiyon çözücü fazına etkili kütle transferini sağlamak ve iyi bir emülsifikasyon oluşturmak için, karıştırma aparatının tipi ve ekstraksiyon ile numune solüsyonu fazları arasındaki temas süresi optimize edilmesi gereken önemli bir parametredir [20]. Vorteks ajitasyonu, ince ekstraksiyon çözücü damlacıklarının oluşumunu kolaylaştırabilir, ekstraksiyon verimliliğini artırabilir ve ekstraksiyon süresini kısaltabilir. Genel olarak, artan vorteks süresi, hedef analitlerin ekstraksiyon çözücüsü ile sulu çözelti arasında kütle transferini hızlandırabilir ve bu nedenle denge süresini en aza indirebilir [16]. Vorteksin etkisi, vorteks karıştırıcısının dönüş hızına ve vorteks süresine bağlıdır. VALLME'de difüzyon mesafesi kısa ve özgül yüzey alanı dengeyi sağlamak için geniş olduğundan, sulu fazdan ara faza kütle transferi yüksek vorteksleme hızlarında daha hızlı olacaktır [21]. Shalash ve ark. [22] yaptıkları çalışmalarında vorteks karıştırıcısının dönüş hızının etkisini 1000-2500 rpm aralığı araştırmış, vorteksleme hızının artmasıyla ekstraksiyon veriminin arttığı görülerek VALLME adımı, ekstraksiyon boyunca vorteks karıştırıcının maksimum hız (2500 rpm) ayarında gerçekleştirildiği bildirilmiştir. Buradan yola çıkarak vorteks süresinin analitlerin ekstraksiyonu üzerindeki etkisini incelemek için deneyler, maksimum vorteks karıştırıcı hızı olan 3000 rpm'de, vorteks karıştırma süreleri ise 1,3 ve 5 dakika olarak çalışılmıştır. 

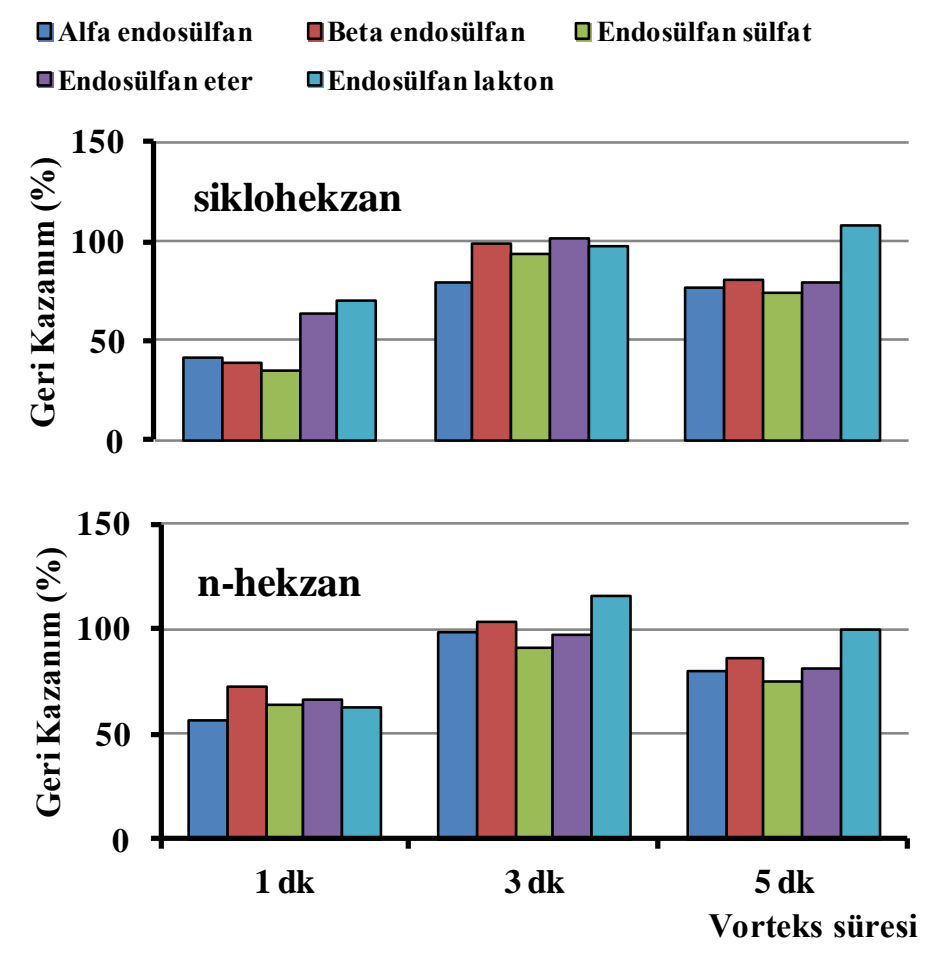

Şekil 7. n-hekzan ve siklohekzan solventleri ile yapılan geri kazanım çalışmalarınavorteks süresinin etkisi (2 $\mathrm{mg} / \mathrm{L}$ endosülfan izomer ve metabolit konsantrasyonu, $200 \mu \mathrm{L}$ solvent hacmi, $10 \mathrm{~mL}$ numune hacmi).

Elde edilen sonuçlar Şekil 7'de gösterilirken, her iki çözücü için de ekstraksiyon veriminin, vorteksleme süresi 1 dakikadan 3 dakikaya çıkarıldığında arttı̆̆ 1 ve bundan sonra ise bir miktar azaldığ bulunmuştur. Böylece 3 dk'da dengeye ulaşılarak ekstraksiyon çözücüsü ile sulu numune arasındaki temas yüzeyi büyük ölçüde artırılmış ve bunun sonucu olarak da kütle transferi artırılarak ekstraksiyon verimleri geliştirimiştir. Vorteks süresinin artırılmasıyla verimlerde meydana gelen bir miktar azalma ise özütleyici ile analitler arası bağların uzun süreli vorteks sonrası kısmen yok olmasına bağlanabilir [16]. Li ve ark. [16] yaptıkları çalışmalarında, vorteks süresinin analitlerin geri kazanılması üzerindeki etkisini incelemek için deneylerini, vorteks hızı 500 rpm'de tutarak farklı vorteks süreleriyle $(0,1,2,3$, 4,5 ve 6 dakika) gerçekleştirmiştir. Vorteks süresi 0 'dan 2 dakikaya çıkarıldığında sinyal değerlerinin yükseldiği, sonrasında 4 dakikada hafif bir azalma olduğu ve daha sonra hızla düştüğü bildirilmiştir.

\section{Sonuçlar ve Öneriler}

Endosülfan izomerleri ve metabolitlerinin vorteks destekli s1v1 siv1 ekstraksiyonunun optimizasyonu için yapılan geri kazanımı çalışmalarında elde edilen sonuçlar aşağıdaki gibi özetlenebilir:

- Ekstraksiyon işleminde kullanılacak çözücü seçimi için yapılan deneysel çalışmalardan çıkan sonuçlar neticesinde en yüksek geri kazanım verimlerine siklohekzan ve n-hekzan çözücülerinde ulaşılmıştır.

- Sonrasında VALLME yönteminin optimizasyonu için sırasıyla çözücü hacmi, numune hacmi ve ekstraksiyon süresinin etkisi araştırılmışıtır. Deneyler sonucunda $200 \mu \mathrm{L}$ çözücü hacmi, $10 \mathrm{~mL}$ numune hacmi ve $3 \mathrm{dk}$ vorteks süresi her iki çözücü için de optimize edilmiştir.

- $\quad \alpha$-endosülfan, $\beta$-endosülfan, endosülfan sülfat, endosülfan eter ve endosülfan lakton için geri kazanım oranlar siklohekzan için sırasıyla; \%79.56, 99.34, 93.28, 101.85 ve 97.43 olarak elde edilirken, n-hekzan için bu değerler sırasıyla; \%99.06, 103.06, 91.1, 96.79 ve 115.31 olarak belirlenmiştir. $\mathrm{Bu}$ sonuçlar neticesinde VALLME'de kullanılacak ekstraksiyon solventi n-hekzan olarak belirlenmiştir. 


\section{Teşekkür}

Bu çalışma Mehmet TÜRKYILMAZ'ın doktora tezinin bir kısmından üretilmiştir. Bu çalışma Yüksek Öğretim Kurumu tarafindan "2014-ÖYP-106" no.lu proje ile ve TÜBİTAK tarafından "2211-C Öncelikli Alanlar Bursu” ile desteklenmiştir.

\section{Yazarların Katkısı}

Yazarların makaleye olan katkıları eşittir.

\section{Çıkar Çatışması Beyanı}

Yazarlar arasında herhangi bir çıkar çatışması bulunmamaktadır.

\section{Araştırma ve Yayın Etiği Beyanı}

Yapılan çalışmada araştırma ve yayın etiğine uyulmuştur.

\section{Kaynaklar}

[1] Bajpayee M., Pandey A.K., Zaidi S., Musarrat J., Parmar D., Mathur N. 2006. DNA damage and mutagenicity induced by endosulfan and its metabolites. Environmental and Molecular Mutagenesis, 47 (9): 682-692.

[2] Goebel H., Gorbach S., Knauf W., Rimpau R., Huttenbach H. 1982. Properties, effects, residues, and analytics of the insecticide endosulfan. Resisue Reviews, 83: 1-165.

[3] Li Y., Macdonald R., 2005. Sources and pathways of selected organochlorine pesticides to the Arctic and the effect of pathway divergence on $\mathrm{HCH}$ trends in biota: A review. Science of the Total Environment, 342 (1-3): 87-106.

[4] Janssen M.P.M. 2011. Endosulfan: A closer look at the arguments against a worldwide phase out.

[5] Weber J., Halsall C.J., Muir D., Teixeira C., Small J., Solomon K. 2010. Endosulfan, a global pesticide: A review of its fate in the environment and occurrence in the Arctic. Science of the Total Environment, 408 (15): 2966-2984.

[6] Hwang J.I., Lee S.E., Kim J.E. 2015. Plant uptake and distribution of endosulfan and its sulfate metabolite persisted in soil. PloS One, 10 (11): e0141728.

[7] Shah N.S., He X., Khan H.M., Khan J.A., O'Shea K.E., Boccelli D.L. 2013. Efficient removal of endosulfan from aqueous solution by UV-C/peroxides: a comparative study. Journal of Hazardous Materials, 263: 584-592.

[8] Vidal J.M., Plaza-Bolanos P., Romero-González R., Frenich A.G. 2009. Determination of pesticide transformation products: A review of extraction and detection methods. Journal of Chromatography A, 1216 (40):6767-6788.

[9] Ahmad W., Al-Sibaai A., Bashammakh A., Alwael H., El-Shahawi M. 2015. Recent advances in dispersive liquid-liquid microextraction for pesticide analysis. Trends in Analytical Chemistry, 72: 181-192.

[10] Płotka-Wasylka J., Owczarek K., Namieśnik J. 2016. Modern solutions in the field of microextraction using liquid as a medium of extraction. Trends in Analytical Chemistry, 85: 4664.

[11] Yiantzi E., Psillakis E., Tyrovola K., Kalogerakis N. 2010. Vortex-assisted liquid-liquid microextraction of octylphenol, nonylphenol and bisphenol-A. Talanta, 80 (5) :2057-62.

[12] Ojeda C.B., Rojas F.S. 2018. Vortex-assisted liquid-liquid microextraction (VALLME): The latest applications. Chromatographia, 81 (1): 89-103.

[13] Karadaş C., Kara D. 2017. Dispersive liquid-liquid microextraction based on solidification of floating organic drop for preconcentration and determination of trace amounts of copper by flame atomic absorption spectrometry. Food Chemistry, 220: 242-248. 
[14] Çabuk H., Y1lmaz Y., Yıldız E. 2019. A vortex-assisted deep eutectic solvent-based liquid-liquid microextraction for the analysis of alkyl ggallates in vegetable oils. Acta Chimica Slovenica, 66 (2): 385-394.

[15] Jia C., Zhu X., Wang J., Zhao E., He M., Chen L. 2010. Extraction of pesticides in water samples using vortex-assisted liquid-liquid microextraction. Journal of Chromatography A, 1217 (37):5868-5871.

[16] Li T., Song Y., Li J., Zhang M., Shi Y., Fan J. 2020. New low viscous hydrophobic deep eutectic solvents in vortex-assisted liquid-liquid microextraction for the determination of phthalate esters from food-contacted plastics. Food Chemistry, 309: 125752.

[17] Liu X., Liu C., Qian H., Qu Y., Zhang S., Lu R. 2019. Ultrasound-assisted dispersive liquid-liquid microextraction based on a hydrophobic deep eutectic solvent for the preconcentration of pyrethroid insecticides prior to determination by high-performance liquid chromatography. Microchemical Journal, 146: 614-621.

[18] Vidal L., Canals A., Kalogerakis N., Psillakis E. 2005. Headspace single-drop microextraction for the analysis of chlorobenzenes in water samples. Journal of Chromatography A, 1089 (1-2): 25-30.

[19] Papadopoulou A., Román I.P., Canals A., Tyrovola K., Psillakis E. 2011. Fast screening of perfluorooctane sulfonate in water using vortex-assisted liquid-liquid microextraction coupled to liquid chromatography-mass spectrometry. Analytica Chimica Acta, 691 (1-2): 56-61.

[20] Zaruba S., Vishnikin A.B., Andruch V. 2016. A novel vortex-assisted liquid-liquid microextraction approach using auxiliary solvent: Determination of iodide in mineral water samples. Talanta, 149: 110-116.

[21] Lian Y., Qiu X., Yang Y. 2014. Vortex-assisted liquid-liquid microextraction combined with HPLC for the simultaneous determination of five phthalate esters in liquor samples. Food Analytical Methods, 7 (3): 636-644.

[22] Shalash M., Makahleh A., Salhimi S.M., Saad B. 2017. Vortex-assisted liquid-liquid-liquid microextraction followed by high performance liquid chromatography for the simultaneous determination of fourteen phenolic acids in honey, iced tea and canned coffee drinks. Talanta, 174: $428-435$. 